\title{
DOS PARADIGMAS DE DRAMA HISTÓRICO CONTEMPORÁNEO: EL ESPAÑOL DOMINGO MIRAS Y EL NEGROAFRICANO AIMÉ CÉSAIRE
}

ANDRÉ MAH

Universidad de Yaundé I

maandres55@yahoo.fr

\section{RESUMEN}

El hecho de que un pueblo, al encararse con un escenario, pueda enfrentarse con su pasado histórico, y por lo tanto, tomar conciencia histórica de sí mismo y de su destino, a través de la acción catártica, da una significación coherente a lo que entendemos por «teatro histórico».

Palabras Clave: teatro; Historia; analepsis; catarsis; Domingo Miras; Aimé Césaire.

\section{RÉSUMÉ}

Le fait par lequel un peuple, face à la scène, puisse se retrouver face à face avec son passé historique et, par conséquent, prendre conscience de son existence et de son destin à travers l'action catharstique, donne une signification cohérente au concept de «théâtre historique».

Mots-CleF: théâtre; Histoire; analepse; catarsis; Domingo Miras; Aimé Césaire.

El drama histórico (Romera, 1999) y la novela histórica (Romera, 1996) nacen del afán y de la necesidad de los dramaturgos y novelistas de hacernos comprender el pasa- 
do recurriendo a la Historia. Ménendez Pelayo sitúa muy bien el fenómeno en su discurso de ingreso a la RAE de la Historia el 13 de mayo de 1893:

Y vienen siglos de reflexión y de análisis en que los poetas cultos sienten la necesidad de refrescar su inspiración en la fuente de lo real y acuden a la historia con espíritu desinteresado y arqueológico, naciendo entonces el drama histórico de Shiller y la novela histórica de Walter Scott, que influyen a su vez en los progresos del arte histórico, y en ciertos sentidos la renuevan (Lozano, 1986: 116).

El texto literario histórico se convierte así en esa otra red que tendemos sobre la realidad para comprender nuestra situación vital, la del ser humano en el universo (G. Gullón, 1996: 65).

El drama histórico es un relato - relato en el sentido que le da Everaert Desmedt (1981), o sea representación de un acontecimiento - que se caracteriza por presentar secuencias y personajes identificables fuera del contexto literario, ya que han sido recreados a partir de unos personajes y unos hechos no ficticios sino pertenecientes a lo que se considera «realidad histórica». Este relato histórico utiliza materiales de la realidad para construir una nueva configuración donde, con determinados procedimientos e intenciones, se entrelazan hechos documentados, con otros imaginarios, así como personajes históricos, reconocibles fuera del texto, con personajes imaginarios. Del uso de elementos reales dentro de la ficción depende la mayor o menor «exactitud documental» que ciertos críticos encuentran en los dramas y novelas históricas, de modo que se ha podido decir (¡erróneamente!) que el drama (o novela) histórico es la obra en la que la exactitud documental es más importante que la ficción (Ravis-Françon, 1975: 419).

Sin embargo, el teatro histórico, cuando nos «relata» sucesos pasados conocidos, no se propone como práctica historiográfica, sino que asume acontecimientos o personajes históricos como «contenidos» de una reconstrucción que, más o menos explícitamente, está entretejida con la conciencia contemporánea, con alusiones a la realidad del autor y del espectador. Es también obvio que recorriendo el mismo itinerario histórico, pueden darse versiones opuestas:

a) Se puede proponer de nuevo un acontecimiento según la óptica ideológica vigente, y de esta manera, el espectador se encontrará frente a un pasado consabido, que ha conocido ya a través de los manuales institucionales.

a) O al revés, según un punto de vista «inesperado», que trastorna la recepción conocida del pasado, muestra grietas y hendiduras que encuadran perspectivas diferentes, induciendo al espectador a enfrentarse con la sorpresa y a reflexionar.

He aquí, reunidas, las dos tendencias de teatro histórico que configuran el panorama dramático en general que podemos concretar con el ejemplo español, pero difícilmente ambas en el ámbito negroafricano: la primera, de opción lenitiva, con E. Marquina, J. M. Pemán ${ }^{1}$ a la cabeza, se asoma al pasado con intento consolatorio, evocando la imagen idílica de la España imperial, en escenas brillantes y con encantadoras retóricas donde se

\footnotetext{
${ }^{1}$ Consúltese Francisco Ruiz Ramón (1992).
} 
plasman momentos y figuras memorables en los que se hacen relucir la dignidad, el patriotismo y la grandeza de la tradición nacional como receta aseguradora y posición ideológica en tiempo de crisis.

La otra vertiente, con Valle-Inclán, Lorca y Buero Vallejo como puntos de referencia, se dedica a la presentación dramática con la voluntad de sacar a la luz lo que las historias oficiales olvidan o sofocan, de diversos momentos de la historia, en un ejercicio que casi podría calificarse como una propuesta de autocrítica colectiva.

En esta última tendencia se sitúan los dos paradigmas que hemos elegido para exponer las grandes líneas del teatro histórico contemporáneo:

1) En primer lugar, el español Domingo Miras, heredero de Valle-Inclán y Buero Vallejo y considerado por Francisco Ruiz Ramón (1992) como el creador de uno de los más ricos jugosos y espléndidos castellanos de la actual literatura dramática española.

2) $Y$ en segundo lugar, Aimé Césaire, figura señera de la negritud (Kesteloot, 1970: 1971).

Encauzar el paralelismo de unas situaciones remotas con otras próximas, pero también reflexionar sobre la experiencia histórica de algunos períodos para comprender todo lo que de positivo o negativo en ella se encerraba para ciertos hombres de entonces y de ahora, es el objetivo y el primer punto de contacto de los dos dramaturgos. El escenario es, para ellos, el lugar privilegiado para favorecer la reflexión conjunta sobre el presente y el pasado: es el hilo común que une a los dos a pesar de la distancia geográfica y contextual.

Hubiera sido más rigurosamente científico organizar un análisis concreto que ponga flanco a flanco sus distintas obras (La Saturna, De San Juan a San Gil, Las Brujas de Barahona, Las alumbradas... La Monja Alférez// La tragedia del rey Christophe, Una estación en el Congo etc. ${ }^{2}$ ) en torno a las categorías narratológicas: personaje - espacio tiempo - discurso, para mejor asentar la pertinencia de nuestro propósito.

Pero, en el marco de un artículo — que tiene sus limitaciones- elegimos organizar nuestra exposición sobre tres ejes fundamentales:

- La idea de teatro.

- El modo de operar del drama histórico.

- El resurgimiento del barroco.

\section{LA IDEA DE TEATRO}

Que condiciona el modo de utilización de la Historia. A Césaire tanto como a Miras les convendría bien esta definición que Ricardo Doménech (1993: 152) da del teatro histórico:

\footnotetext{
2 Véase en Bibliografía.
} 
Si desde un punto de vista preceptivo el concepto de teatro histórico resulta extraordinariamente impreciso, este fenómeno de que un pueblo, al encararse con un escenario, pueda encararse con su pasado histórico y, por lo tanto tomar conciencia histórica de sí mismo y de su destino a través de la acción catártica que es peculiar al drama, nos parece, por el contrario, extaordinariamente preciso y entendemos que sólo a partir de aquí la idea de teatro histórico puede tener una significación coherente.

Para ambos, la pretensión del drama histórico es crear las posibilidades concretas para que los individuos reflexionen sobre su propia existencia como algo condicionado históricamente, para que perciban que la historia es algo que interviene profundamente en su vida cotidiana, en sus intereses inmediatos.

En efecto, la inscripción histórica de las obras de Miras y el momento de su escritura dramática nos permite analizar la pertinencia de su producción de signos como forma de crítica. Pérez Minik (1961: 385) escribía al valorar la producción literaria y teatral de posguerra:

Después de nuestra guerra civil, la historia de la convivencia española necesitaba un proceso. De esto no cabe duda.

Mas allá del proceso a la historia de España, las ideas de Miras sobre el teatro histórico son de gran interés, no sólo para entender su propia obra, sino también para explicar la función social del drama histórico español y no español contemporáneo. Para él, la Historia es:

Un enorme depósito de víctimas. Víctimas de muy distinta naturaleza y circunstancias, pero todas igualmente atropelladas por el curso de los hechos, ya se trate de luchadores armados por la libertad, ya de heterodoxos clandestinos o minorías marginales (...). El teatro sigue siendo así esencialmente igual al que fue en otro tiempo, representación catártica del sacrificio del hombre, pero con la importante innovación de que sus antagonistas no son las fuerzas ciegas del destino, sino fuerzas sociales muy concretas que se pueden y se deben identificar (...). De ahí el que la Historia sea tan generosa proveedora de argumentos dramáticos. La Historia es el recuerdo de las injusticias de antes que son, en esencia, las de ahora, de las opresiones y persecuciones de antes que son también las de hoy, el recuerdo de los muertos antes y después, los muertos ya intemporales, que se reencarnan por el escenario (Miras, 1980-81: 21-23).

Desde este enfoque, coincide Aimé Césaire con Domingo Miras. En efecto, las obras del escritor martiniqueño se sitúan en el contexto sociopolítico de lucha por la libertad de los pueblos negroaficanos, contexto en el que el dramaturgo intenta eregirse en despertador de conciencia. El teatrólogo maliano Bakary Traoré (1958: 9) destaca, con este propósito, las funciones sociales del teatro negroaficano:

El teatro negroafricano, como todo arte, responde a las necesidades fundamentales, necesidades del individuo, necesidades del conjunto social: el arte es unificador de hombres, sirve para la cohesión, para la toma de conciencia (...) Pues, en fin, el teatro ha de responder a una necesidad de anticipación: construir los materiales del orden futuro. 
No olvidemos que el momento de escritura del teatro de Césaire es el de las post-independencias africanas, contexto en que, como reconoce José Monleón (1988:5), países enteros han querido fundamentar dudosos proyectos políticos. El recurso al drama histórico también sirve para entender el pasado, e incorporar documentos y experiencias postergados por la visión oficial, es un factor de liberación popular.

\section{EL MODO DE OPERAR}

Fijémonos en dos puntos:

1) La relación de fidelidad o no fidelidad a la Historia.

2) La relación Presente/Pasado como dialéctica.

En el primer punto, Aimé Césaire y Domingo Miras demuestran que para crear un drama histórico, es decir, una versión enriquecedora de personas y acontecimientos pasados, es necesario tener un conocimiento profundo de lo realmente sucedido y de sus causas sociales y psicológicas. Algunos dramas - La tragedia del rey Christophe, Una estación en el Congo, De San Pascual a San Gil, Las brujas de Barahona, etc. ${ }^{3}$ - ofrecen una exactitud documental semejante a la del texto de los historiadores.

Sin embargo, los dramaturgos no tienen porqué ceñirse a una total fidelidad cronológica, espacial o biográfica respecto de los hechos comprobados. Por eso añaden al conocimiento de la Historia, la intuición de la «intrahistoria» posible que los hechos documentados no pueden dar.

Los dos dramaturgos tienen la conciencia de hacer teatro y no historia. Para ellos, el teatro histórico es labor estética y social de creación, que debe no ya refrendar la versión oficial sino «ir por delante de la historia más o menos establecida», abrir nuevas vías de comprensión de la misma e inducir interpretaciones más exactas.

Para ambos, un drama histórico es una obra de invención y el rigor interpretativo a que aspira atañe a los significados básicos y no a los pormenores. Es el caso de La venta del ahorcado que reproduce algunas vivencias de Miras, construidas a partir de la arbitraria redada policial contra la gente de teatro, tras el atentado de la calle del correo de Madrid en septiembre de 1974.

En ocasiones, el drama puede presentar a un personaje principal totalmente histórico, como Lumumba en Una estación en el Congo, de Césaire, pero luego volverse hacia la conciencia y la memoria del personaje, recorrer galerías interiores para revelarnos lo que las fuentes documentales no nos dijeron, su privacidad, este territorio en el que son posibles episodios que si nunca ocurrieron, reflejan sin embargo «formas posibles de verdad».

Ambos dramaturgos construyen sus dramas en torno a un elemento estructural básico: la lucha por la libertad. Miras insiste en esta lucha por la libertad, en una conferencia en la Universidad de Murcia (1989: 17-18) sobre el tema Teatro e historia, al decir recordando a Rousseau:

\footnotetext{
${ }^{3}$ Consúltese el análisis de las determinaciones espaciales y temporales en MAH (1997).
} 
El hombre, libre por naturaleza, cede una parte de su libertad para construir un poder que le garantice el pacífico disfrute de la porción de libertad que le queda. Pues bien, la misión del arte en general y del teatro en particular, es la utópica reivindicación de esta parte de libertad.

En cuanto a Césaire, la problemática de la conquista de la libertad es el punto de partida del acto creador, de su quehacer literario y dramático.

En cuanto a las relaciones Presente/Pasado, como se sabe, todo relato histórico es, en principio, analéptico, y está construido sobre la separación de dos tiempos, el tiempo del objeto narrado y el tiempo del relato propiamente dicho. En el drama histórico, sin embargo, esa separación tiende a borrarse, e incluso a dialécticas que el dramaturgo establece entre el pasado y el presente, entre el que llamamos «tiempo histórico» y el tiempo actual, que es el tiempo del dramaturgo y del espectador, es decir, el tiempo de la construcción del drama, el de su representación y el de su recepción.

El acto de elección y de selección de la materia histórica no es nunca inocente; es siempre un acto de complicidad con el presente. Cuando Césaire y Miras configuran la materia histórica elegida en situaciones conflictivas entre personajes que encarnan fuerzas históricas, situaciones y personajes, podría tratarse de una técnica oblicua para escapar a la censura (real y omnipresente en su país en el momento de escritura y recepción del drama), y de este modo hablar del presente en el pasado o por el pasado.

Sin embargo, no pasa así. Los dramas históricos cesaireanos y mirasianos (igual que los de Buero Vallejo) responden a una doble clave dramatúrgica: remiten a un doble referente y significan, a la vez literal y simbólicamente, en el proceso de recepción de su sentido. Doble clave dramatúrgica, en efecto, por parte del autor en la lectura simultánea de dos sistemas históricos, el de pasado y del presente, entre los cuales, en el proceso de operación de su plasmación dramática (puesta en acción), construye un denso tejido de analogías, no entre elementos singulares, aisladamente, sino entre el haz de relaciones polisémicas y polisemánticas que movilizan todos los elementos dentro del sistema histórico pasado y todos los elementos del sistema histórico presente.

Desde entonces, no es contradictorio que Césaire, por ejemplo, presente una visión contemporánea y futurista a partir de acontecimientos y personajes que pertenecen al pasado. El futuro no puede ser más que un futuro enraizado; así, por ejemplo, la aventura haitiana de Christophe, en La tragedia del rey Christophe, prefigura ciento cincuenta años antes el destino colectivo del pueblo africano.

La tragedia del rey Christophe es fiel a la historia de los negros en dos niveles: la historia de Haití y la de África. En primer lugar, se trata de una historia verdadera, loca y vertiginosa, la de un esclavo cocinero de hace más de ciento cincuenta años, hacia 1818, que, después de combatir a los franceses al lado de otro esclavo rebelado Toussaint-Louverture, libertador de Haití, y de Dessalines, su primer jefe, no imagina nada menos que eregir su país en reino; se hace coronar Rey Henry Christophe, exactamente como Luis XIII, Luis XIV, Luis XV y otros (precisamente porque los franceses, según él, no sienten respeto por las repúblicas: Napoleón lo ha demostrado bien).

Además, se hace construir una Ciudadela, verdadero monumento titanesco, como misterioso desafío a Occidente.

En segundo lugar, paralelamente, la historia de las independencias africanas aclara la de Haití. Los países africanos se encuentran enfrentados a problemas cruciales de elec- 
ción de caminos que seguir, refundición de mentalidades, etc. La tarea es penosa; los imprevisibles avatares de las jóvenes naciones (la intransigencia de la Guinea Conakry de Sekou Touré, el misticismo del Ghana de Kwame N'Krumah...etc) ${ }^{4}$ permiten que Césaire pueda realizar una interpretación magistral de aquel rey negro que hasta entonces era considerado como un tirano o un loco. Comprendemos por qué, al analizar la pieza de Césaire, Mbom (1979: 51) puede titularla: La tragedia del rey Christophe o los países del Tercer Mundo en el alba de sus independencias.

Asociando pasado, presente y futuro, la obra dramática de Césaire se define en una perspectiva pluricontinental bajo el común denominador de la negritud.

La conjunción pasado, presente y la problemática planteada, tanto en Césaire como en Miras, pueden resumirse en estas palabras de Luis Iglesias Feijoo (1988: 19):

No se trata de hablar del presente por medio del pasado, sino más bien de hablar al presente a través de la rememoración de etapas o personajes de la Historia. La presentación dramática de cómo se han producido unos hechos y cuáles han sido las dificultades con que tropezaron ayer sus protagonistas trata de ayudar a descubrir las que anidan en el presente, ocultas casi siempre por la familiaridad con que las soportamos. Si entonces los obstáculos resultaron quizá insalvables, cada obra invita implícitamente a reflexionar sobre las causas de que ello fuera así. Y cuando los personajes terminan en el fracaso, o en la muerte, se está revelando a la vez que, en el curso de la Historia, la violencia produce víctimas, las cuales - y ello no es menos importante- se encuentran casi siempre en el pueblo. Para evitar que el resultado de los procesos históricos siga siendo siempre éste, el dramaturgo considera su deber recordarlo.

\section{RESURGIMIENTO DEL BARROCO}

Para asentar toda esta compleja estructura a la que llamamos drama histórico, los dos dramaturgos recurren al Barroco, entendiendo el término en el sentido de un arte que integra cuanto hay en la vida y no rechaza nada de ella, y por lo tanto, un arte de insumisión a la reglas.

Todas las reglas nacidas de las diversas Artes poéticas que modelan tradicionalmente la tragedia (división convencional en cinco actos subdivididos en escenas, las reglas de las tres unidades, la verosimilitud, la decencia, etc.). Miras y Césaire, por su formación, las conocen muy bien; sin embargo, deliberadamente, han decidido transgredirlas o ignorarlas. Parecen respetar más los preceptos que V. Hugo (Lagarde \& Michard, 1973: 18) escribía en el prefacio de Marie Tudor:

Sería la mezcla en la escena de cuanto en la vida se mezcla; sería un motín por allí y una charla amorosa por acá... sería la risa, serían las lágrimas... el bien, el mal lo alto, lo bajo, la fatalidad, la providencia, el genio, el azar, la sociedad, el mundo... y encima de todo eso se sentirá planear algo grande.

Miras, en múltiples ocasiones, ha señalado el barroquismo como nota característica de su teatro. En sus Fragmentos de la Memoria, por ejemplo, ofrece su idea de teatro:

\footnotetext{
${ }^{4}$ Estos temas los desarrolla Kesteloot \& Kotchy (1993).
} 
Este rito colectivo vibrante y opulento, confuso y potente, jovial y doloroso, no es ciertamente el teatro ordenado y monolítico, con situaciones medidas y versos cincelados de un Racine, sino el teatro barroco, fulgurante y oscuro, que vulnera toda norma llevado de su impulso transgresor y se retuerce sobre sí mismo como una columna salomónica cargada de ramas de vid y dorados racimos de bronce. Teatro barroco de nuestro tiempo, teatro de fuerza y de audacia que cada vez lleva más lejos el límite de su osadía... (Miras, 1980: 74).

En cuanto a Césaire, también indiferente a las imposiciones de la dramaturgia clásica, considera el teatro como un arte completo, un arte de síntesis y de integración y crea así un teatro moderno que manifiesta la mayor libertad creadora al nivel de la escritura dramática.

Las consecuencias de esta concepción del teatro son obvias:

- Una plétora de personajes, procedentes de todas las capas sociales y de los diversos orígenes, como en la vida. A veces en este afán de restituir la vida, los dos dramaturgos rozan lo inverosímil convocando a escena a seres fantásticos, introduciendo así prácticas mágicas, brujeriles o simplemente irreales (bruja, magos, o seres nacidos del subconsciente de los personajes). Se crean, por lo tanto, espacios que pueden plantear serios problemas de representación.

- Una escenificación de pasiones desencadenadas y exacerbadas: el universo teatral de Miras y Césaire está salpicado de escenas de una violencia y crueldad que rozan la indecencia: agresiones y violencias sexuales, orgías, torturas multiformes de un sadismo morboso, asesinatos de una brutalidad que sólo tiene réplica en el mundo animal (y desgraciadamente en el nuestro también).

Podríamos citar más rasgos. En resumen, lo que caracteriza a Miras y a Césaire es la voluntad de romper con una estética canónica y sinónima de subordinación y de aceptación servil. Son escritores rebeldes, y al igual que sus actantes sujetos ${ }^{5}$, en busca de un nuevo orden humanitario: por eso, sus obras llevan ostentosamente la marca de esa rebeldía.

\section{CONCLUSIÓN}

En resumen, a pesar de que los contextos evocados son diferentes, en Miras y en Césaire, los móviles de la escritura son, en cierto nivel, los mismos; y su concepto del teatro histórico es igual: la historia viene a ser un semillero para el dramaturgo. En el oscuro interior de sus baúles guarda una multitud de fantasmas, dispuestos para su evocación. Son las sombras de gentes que quisieron ser libres, que, de una manera u otra lucharon por su libertad. Su cólera y su fuerza pueden aún germinar y crecer en una nueva tierra, en otros corazones (Miras, 1980-81: 23).

En esta doble captación simultánea del doble significado ideológico de la acción (pasado/presente) tiene lugar la síntesis que permitirá a la representación del drama históri-

\footnotetext{
5 Véase el análisis actancial realizado por Mah (1997).
} 
co cumplir su doble función catártica y didáctica. Los poderes catárticos y didácticos se producen en las obras de Césaire y Miras porque la temática histórica está utilizada con intención crítica. En los dos dramaturgos hay un deseo de reorganizar los desórdenes de la Historia y crear un mundo más coherente. Si Césaire, por ejemplo, exalta y sublima ciertas figuras cumbres de la Historia de su pueblo, es para responder a la invitación de Zadi Zaourou (1970):

Los escritores africanos, al dirigirse a la Historia, al explotar sus innumerables recursos, han de crear imágenes fuertes, crear héroes que sean modelos un poco como el África tradicional lo hacía cuando se dirigía a su propio pasado.

En un continente convertido en caos en este inicio del siglo XXI, como es África hoy en día, la obra de renovación debe emprenderse cueste lo que cueste, a pesar de los dramas nacionales (guerras civiles, divisiones políticas, luchas intestinas, etc.), muchas veces fomentadas, financiadas, patrocinadas por antiguas potencias colonizadoras. Pertenece al hombre que asume la dirección de la nación, realizar el presente en función del futuro. Por eso, y por su estatura mítica, Lumumba o Christophe, retrato del rebelde, encarnan la ascensión del África del siglo XXI hacia un futuro de unidad y de prosperidad.

La producción teatral de Miras y Césaire irradia en el aire del tiempo como un himno universal contra toda forma de opresión y de envilecimiento del hombre, haciendo estallar las fronteras de Haití, de España y de África, para reunir a todos los hombres del mundo bajo la bandera de la paz y de la libertad.

La perspectiva crítica que ofrecen los dramas es peculiar. El lector-espectador puede observar que, hoy, se ha conseguido llevar a la práctica lo que en siglos pretéritos era desdeñosamente rechazado como irrealizable: una nueva dimensión se abre frente a lo que en la actualidad se considera como fuera del alcance de la mano del hombre. En la sala teatral, se instaura una aguda conciencia de transitoriedad, que conduce a entender el presente como un devenir, como un momento también histórico y mutable, y objeto, por tanto, de la acción humana. Es éste el sentido del «posibilismo» de Buero Vallejo, con una visión esperanzada y esperanzadora del hombre y del mundo como ofrece el drama histórico contemporáneo.

BIBLIOGRAFÍA

\section{Producción dramática}

\section{I.1. Obras de Miras}

Miras, D. (1974): La Saturna. Pipirijaina, Texto 4, 15-79.

- (1985): Las alumbradas de la Encarnación Benita. Madrid: La Avispa.

- (1986): La venta del Ahorcado. Murcia: Universidad.

- (1988): De San Pascual a San Gil. Madrid: Alhambra.

- (1991): El doctor Torralba. Roma: Ed. Bulzoni.

- (1992a): La Monja Alférez. Murcia: Universidad.

- (1992b): Las brujas de Barahona. Madrid. Espasa Calpe. 


\section{I.2. Obras de Césaire}

CÉSAIRE, A. (1956): Y los perros callaban. Buenos Aires: Librerías Fausto, 1974.

- (1963): La tragedia del rey Christophe. Barcelona: Barral, 1972.

- (1967a): Une saison au Congo. París: Seuil.

— (1967b): Una tempestad. Barcelona: Barral, 1972.

\section{Bibliografía crítica}

DoMÉneCh, R. (1993): El teatro de Buero Vallejo. Madrid: Gredos.

Everaert Desmedt, N. (1981): Semiotique du récit. Cabay: Louvain-La-Neuve.

Gullón, G. (1996): «El discurso histórico y la narración novelesca (Juan Benet)», en José Romera Castillo (editor), La novela histórica a finales del siglo XX, 63-73. Madrid: Visor Libros.

Iglesias FeiJoo, L. (1988): «Circunstancia y sentido de El Concierto de San Ovidio: El teatro de Buero Vallejo», Estreno XIV , 1, 18-21.

Kesteloot, L. (1970): Négritude et situatión coloniale. Yaoundé: Clé .

- (1971): Les écrivains noirs de Langue française. Bruxelles: Université.

Kesteloot \& Kотсhy (1993): Aimé Césaire, l' homme et l'oeuvre. París: Présence Africaine.

LAGARDE \& RichaRD (1972): La littérature française. Paris: Bordas.

LozAno, J. (1986) El discurso histórico. Madrid: Alianza.

Mah, A. (1997): Aproximación Semiótica al teatro de Domingo Miras y Aimé Césaire. Madrid: UNED (en microficha). Tesis de doctorado, dirigida por José Romera Castillo.

Мвом CL (1979): Le thêatre d'Aimé Cesaire. París: Nathan.

MiRAs, D. (1980): «Fragmentos de la memoria», Primer Acto, 185, 76-77.

- (1989): «Teatro e historia», Conferencia (inédita) pronunciada en Murcia en Diciembre.

Monleón, J. (1988): «Historia y drama durante la dictadura», Estreno, 1, 5-6

PÉREZ MiNIK, D. (1961): Teatro europeo contemporáneo. Madrid: Guadarrama

RAVIS-Françon, S. (1975): «Temps historique et temps romanesque dans La Semaine Sainte», Revue d' Histoire Litteraire de la France, 75, 419.

ROMERA CASTILLO, J. (editor) (1996): La novela histórica a finales del siglo XX. Madrid: Visor Libros.

- (1999): El teatro histórico (1975-1998): textos y representaciones. Madrid: Visor Libros.

Ruiz Ramón, F. (1992): Historia del teatro español. Siglo XX. Madrid: Cátedra.

TRAORÉ, B. (1958): Le théâtre négroafricain et ses fonctions sociales. París: Présence Africaine.

ZAdI ZAOROU, B. (1970): L'Esthétique de Césaire à travers leCahier d'un retour au pays natal: Abidjan: Fac. Lettres (inédita). 